\title{
Female Condoms as a Preventive Measure against HIV/AIDS Infection among University Students in Gaborone, Botswana
}

\author{
Galeage Kaelo1, Brothers Wilright Malema² \\ ${ }^{1}$ Research Unit, Botswana Central Bank, Gaborone, Botswana \\ ${ }^{2}$ Department of Economics, Faculty of Social Sciences, University of Botswana, Gaborone, Botswana \\ Email: malemabw@mopipi.ub.bw
}

Received 3 April 2014; revised 13 May 2014; accepted 25 June 2014

Copyright (C) 2014 by authors and OALib.

This work is licensed under the Creative Commons Attribution International License (CC BY). http://creativecommons.org/licenses/by/4.0/

(c) (i) Open Access

\section{Abstract}

This paper seeks to investigate the predictors of female condom use amongst female university students in Gaborone, Botswana. The study used primary data through the administration of a questionnaire amongst randomly selected respondents to determine the factors behind the use of female condoms. Since the dependent variable had three outcomes, multinomial logistic regression was used. It was found out that only known HIV status was inversely related to the use of the female condom. The other variables, namely age, perceived exposure to HIV infection, perception about the female condoms and the respondents perceived risk were positively and significantly related to the use of the female condom. The paper concluded by pointing out that the limited use of female condoms should not be construed as indicative of the absence of safer sexual practices until some factors, namely the use of the male condom and partner behaviors are brought on board. Notwithstanding this apparent omission, the paper culminates by appealing for continued or even intensified sex education on the importance of the female condom particularly in view of the HIV and AIDS scourge.

\section{Keywords}

Students, Female Condoms, HIV/AIDS, Botswana

Subject Areas: Behavioral Economics, Socioeconomics

\section{Introduction}

The devastating socio-economic effects of HIV/AIDS have been well documented. The impact has stretched resources which are often limited and diverted, some from productive and investment ventures as damage control 
measures are put in place. This damage control measures it can be argued serve to protect the very investments that have afore been undertaken. Without such measures such as antiretroviral therapies, economies particularly those substantively affected by HIV/AIDS like the Botswana one might have lost the human resource for which the country have so immensely invested in. However, there are mixed results as to the trend of HIV infections and if at all there is any evidence to declining trends, such is quite marginal. It has been pointed out that females are more infected than males despite the observation that the reverse was true at the onset of HIV/AIDS [1]. This pattern in which more women than men are infected has led researchers to investigate the cause of such changes. Though a number of reasons such as biological factors have been mentioned, gender imbalance has stood out as the driving force behind this pattern. It is upon this recognition that female condoms have been perceived as a betterment elixir to the reduction of the proliferation of this pattern since it accords females a tool they can use to protect themselves. It is our view though, that the effectiveness and potential of a female condom in an environment of gender imbalance will not be fully exploited and realized. It is however, a good measure that will foster prevention of transmission not only of HIV/AIDS but of other sexually transmitted infections and also act as deterrence to unwanted pregnancies particularly when accepted across the sex divide. Despite the challenges faced by amongst others gender imbalance, we seek to investigate the use of the female condoms amongst university students in Gaborone the capital city of Botswana, and the factors associated with such use. This we believe will shed more light on the dynamics associated with the use of the female condoms and build on that to promote its use thereby helping curb the further spread of HIV/AIDS and other sexually transmitted infections.

\section{HIV Prevention}

Condom use is one of the most effective means of preventing infection from HIV/AIDS and other sexually transmitted diseases [2]. Despite extensive condom promotion efforts, condom use in sub-Saharan Africa remains very limited ([3]).

The male condom until recently was the only barrier available for the prevention of HIV and most sexually transmitted infections (STIs). The female condom offers an additional option that enables women to protect themselves from HIV and other STIs as well as unwanted pregnancies. The female condom has an important role in HIV prevention [4].

The female condom does not replace the male condom as a means of protection. Studies show that the introduction of female condoms in settings where the male condom is also available has resulted in an increased incidence of protected sex acts. For example, a study in Thailand showed that when both female and male condoms were available to users, STI incidence rates were reduced by a quarter.

Laboratory studies have found female condoms to be impermeable to sexually transmitted infections, including HIV, one of the most common STIs occurring in women. It has been found to give comparable levels of protection against STIs and pregnancy as the male condom. Research confirms that the use of the female condom has no serious side effects. It does not produce irritation or allergic reactions in people sensitive to latex [5].

The World Health Organization [6] outlined four main advantages of using the female condoms:

- Acceptability studies among various groups of women, including young married women and formal sex workers in Malawi, Kenya, Cameroon and Thailand have cited that women found control over their own sexual health as the biggest advantage of the female condom. This is because they can initiate its use, and they can insert the condom well before sexual intercourse.

- The female condom can be used with both water-based and oil-based lubricants without compromising the technical integrity of polyurethane. This is an advantage to many who find water based lubricants hard to find and obtain.

- Because it covers both the internal and much of the external female genitalia, it offers more extensive barrier protection against STI transmission.

- No special storage arrangements are needed because polyurethane is not affected by changes in temperature and humidity.

In most parts of the world, individuals, communities and their leaders struggle with the best way to address concerns about HIV and AIDS. For Botswana, the HIV/AIDS epidemic represents one of the most serious social problems. The rapid spread of infection and AIDS in Botswana over the past years has been tremendous. UNAIDS estimates indicate that by the end of 1999, at least one in four adults in Botswana was living with HIV. The 2008 BAIS III data yielded a national prevalence rate of $17.6 \%$ which is an increase from the $17.1 \%$ that was recorded in 2004 by the BAIS II survey. 


\section{Gender Imbalance}

Previously, in the face of partner refusal to use a male condom, women's sole option for self protection was to refuse sex, and some succeeded. But for others this strategy was problematic; with the possible outcome of violence. Women now have a negotiation tool that, in many circumstances, can be used in ways that are not threatening (and may indeed be soothing) to their partner. HIV/AIDS infection rates are expected to be reduced as one of the positive outcomes of using the female condom as an empowerment tool. For many reasons involving economic and social inequalities, as well as gender power dynamics, women may be unable to negotiate with their male partners to use male condoms consistently. Thus, there is an urgent need to provide expanded options for women to protect themselves from acquiring HIV and STIs. The female condom is one option that has been proposed. Approved for use in protection against STDs and unintended pregnancy, the female condom has been estimated to reduce the rate of STD transmission by $97 \%$ when used exactly as recommended [7].

The female condom provides the opportunity for women to actively protect themselves from HIV infection. It is a method they can choose and initiate. It enables them to be in a position where they learn about their reproductive health in general, which is an important building block in HIV prevention. When women protect themselves from HIV infection, they have an increased sense of self-worth. This could prove to be one of the most important elements in fighting the AIDS epidemic [8].

Because women can initiate the use of the female condom compared to the male condom, the method is believed to make it easier for women to protect themselves against sexually transmitted infections (STIs), including HIV infection but evidence is lacking about factors associated with using the female condom consistently [9].

Socio-cultural factors may play a role in dissuading the use of the female condom. For example, gender dynamics may limit women's ability to negotiate use of a female condom, adolescent girls and women may feel shy to buy the female condom for fear of being seen as promiscuous. Many couples do not view themselves as the intended users of the female condom. For example, some see the female condom as a product for commercial sex workers, while others perceive it as something used by the more educated or elite. Since the female condom was introduced in Botswana in 2002, its use has been very low [10] (Mmegi Newspaper, 2010 April 26), therefore it is of importance to add to the existing literature by investigating the socio-economic factors that affect the use of the female condom, especially amongst the age group that is considered most affected by HIV/ AIDS [11].

The female condom can be used as a tool to empower women. The availability of the female condom has an additive effect which consists of a direct protection effect from women's use of the condom and an indirect effect that increases the use of the male condom owing to the use of the female condom as a negotiation tool and will result in greater protection [12]. The female condom has therefore been shown to contribute to women's sense of empowerment, especially if supported by education and informational activities. If women gain control over their reproductive health, it will result in tremendous advances in social and economic status for women.

\section{Brief Review of Literature}

According to the theoretical model for socioeconomic influences on condom use, occupation and educational levels are positively associated with higher levels of safe sex practices [13]. The level of education indicates access to financial resources, information, and more liberal attitudes toward sexual behavior. Well educated individuals are also more likely to be knowledgeable about sex education and have higher career aspirations and hence engage in safer sexual practices and the protection against STDs [14].

Meekers and Richter [15] conducted a study in Zimbabwe a year after a mass marketing campaign for the female condom in the country. Logistic regression analysis was conducted to assess factors associated with ever-use of the female condom and consistent use (always or often) with marital and regular non-marital partners. It documents that prior experience with the male condom is associated with the use of the female condom and may improve consistency of use of the female condom. The results of the study also show that perceived affordability and ease of use of the female condom are strong predictors of female condom use for both male and female consumers.

Gilbert et al., [16] undertook a study to describe the predictors of female condom use among 96 women exchanging sex for money and drugs on the streets of New York. The findings of the study were that ethnicity is significantly associated with the use of the female condom. Hispanic women were more likely to try the female 
condom than black and white women. According to the study, age is also a strong factor in determining the use of the female condom. Women aged 25 to 34 are more likely to try the device. Women living with a partner (cohabitation) are likely to try the female condom compared to those who are married. Awareness about the female condom is also significant in determining the use of the female condom. Participants who had a Sexually Transmitted Disease (STD) and those who had been tested for HIV were more likely to have tried the female condom than women without such a history.

In Florida, Harrison et al., [17] instructed 231 women aged 18 to 45 years on the use of the female condom and encouraged them to try the device. The women were asked about their reaction before and after the use of the female condom and the responses were measured with a five-point Likert response scheme. The study found that the female condom is mostly used by women who are young, single and those who have an education level less than high school. The study indicated that these are characteristics of women at higher risk of being infected with Sexually Transmitted Diseases (STDs).

A study done by Macaluso et al., [18] in Alabama (USA), found that women who are employed or who have a regular partner are more likely to try the female condom. Results on ethnicity reported that users of the female condom are mostly black women. A large proportion of the participants used both the male and female condom. According to the study, the female condom appears to play a role in allowing inconsistent users of the male condom to achieve high protection rates by mixing both types over time.

A cost effectiveness study demonstrated that female condom promotion programs would save public health expenditures for treatment in both low and high risk groups such as women with one casual partner and commercial sex workers. The study also reported that women are more likely to use the female condom if they believe that it provides better efficacy over the male condom. Furthermore it was found that women were more likely to try the female condom at least once with their spouse and boyfriend but they were less likely to try the device with a new partner [19].

\section{Data Source}

A structured questionnaire was used to ask study participants about their demographic characteristics, sexual behavior, female condom use, and attitudes and beliefs related to the use of the female condom. The questionnaires were administered to a sample of 100 respondents. The questionnaire were self-administered to respondents and consisted of both closed and open-ended questions.

\subsection{Sampling Technique}

The study used the stratified random sampling technique. The respondents in different categories were classified into strata (groupings). Respondents were then randomly selected. The advantage of random sampling is that, it is representative of all subjects who participate but the main limitation of this method of sampling is that it can result in biasness of the results.

\subsection{Frequency of Use of the Female Condom}

The dependent variable is a three-category measure of condom use, which distinguishes nonusers, occasional users and consistent users. The variable is measured with responses to the question, "In the past 3 months, how often did you use a condom (female condom)?" Respondents who provide "never" as the response to the question are recorded as nonusers, respondents who report "always" are recorded as consistent users and those reporting having "sometimes" used the female condom are recorded as occasional users.

\section{Ethical Considerations}

Permission was obtained from the Ministry of Health to conduct the study and responses given by the respondents were treated with absolute confidentiality. The questionnaire was therefore designed in such a way that respondents were not required to give their names when answering the questionnaire.

\section{Empirical Model}

The study used the multinomial logit model because the dependent variable in question consists of more than 
two categories (three categories). There are two types of choice sets: Ordered and Unordered but this study focused on the ordered choice.

Although the multinomial logit model has achieved an established place in choice analysis, its limitations in accounting for differential substitutability among alternatives particularly as embodied in its independence of irrelevant alternatives has become widely known [20].

Schmidt and Strauss [21] estimated a multinomial logit model as follows:

$$
\operatorname{Prob}\left(Y_{i}=j\right)=\frac{e^{\beta_{j}^{t}} x_{i}}{\sum_{k=0}^{4} e^{\beta_{k}^{t}} X_{i}}
$$

where $j=0,1,2$, Consistent use $=0$, Inconsistent use $=1$, Nonuse $=2$.

The estimated equations provide a set of probabilities for the $J+1$ choices for a decision maker with characteristics $x_{i}$.

Only $J$ parameter vectors are needed to determine the $J+1$ probabilities. The model implies that we can compute $J$ log-odds ratios:

$$
L_{i}=\ln \left[\frac{P_{i j}}{P_{i k}}\right]=x_{i}^{1}\left(\beta_{j}-\beta_{k}\right)=x_{i}^{1} \beta_{j}
$$

It is the ratio of the probability that the respondent will use the female condom consistently to the probability that they will not use it consistently. $L_{i}$ is the dependent variable, which is the consistent use of the female condom and it is the logarithm of the odds that a particular decision will be made.

The log-likelihood can be derived by defining for each individual, $d_{i j}=1$ if alternative $\mathrm{j}$ is chosen by individual $i$ and 0 if not, for the $J-1$ possible outcomes. Then, for each $i$, one and only one of the $d_{i j}$ 's is 1 . The log-likelihood is a generalization of that for binomial logit model:

$$
\ln L=\sum_{i=1}^{n} \sum_{j=0}^{J} d_{i j} \ln \operatorname{Prob}\left(Y_{i}=j\right)
$$

Finding adequate fit measures in this setting presents the same difficulties as in the binomial models. If the model contains no covariates and no constant term, then the log-likelihood will be:

$$
\ln L_{c}=\sum_{j=0}^{J} n_{j} \ln \left[\frac{1}{J+1}\right]
$$

where $n_{j}$ is the number of individuals who choose $j$.

The study will estimate the model as follows:

$$
\begin{aligned}
L_{i}= & \propto \\
& +\beta_{1} \text { AGE }+\beta_{2} \text { EDUCATION }+\beta_{3} \text { EXPENDITURE }+\beta_{4} \text { FREQUENCY OF EXPOSURE } \\
& +\beta_{5} \text { KNOWLEDGE ABOUT HIV STATUS }+\beta_{6} \text { PERCEPTION ABOUT THE FEMALE CONDOM } \\
& +\beta_{7} \text { PERCEIVED RISK }+e_{i}
\end{aligned}
$$

\section{Results}

\subsection{Summary of Descriptive Statistics}

Table 1 shows the mean, standard deviation, the minimum and the maximum values of variables for university students. The majority of the respondents interviewed were in their twenties (20's). The restriction of the sample to sexually experienced individuals may partially explain the small proportion of teenagers in the sample. The maximum expenditure was P1750, which the respondents spent on rent. This finding was expected because the mean educational and socioeconomic levels tend to be higher for university students than in the general population. Most of the respondents perceived the female condom to be an effective tool for STI/HIV prevention. Positioning the female condom as a condom rather than as a contraceptive may have allowed women to use it covertly for protection against HIV and other STIs. The average respondent interviewed indicated that they had gone for an HIV test and therefore had knowledge about their HIV status. Whilst the mean number of 
Table 1. Summary statistics for university students.

\begin{tabular}{|c|c|c|c|c|c|}
\hline Variable & Observation & Mean & Standard Deviation & Minimum & Maximum \\
\hline Age & 100 & 23.32 & 1.958561 & 20 & 30 \\
\hline Level of education & 100 & 4 & 0 & 4 & 4 \\
\hline Frequency of use & 100 & 0.21 & 0.4093602 & 0 & 1 \\
\hline Food & 100 & 474.2 & 127.0741 & 200 & 1000 \\
\hline Rent & 100 & 542.8 & 315.8093 & 0 & 1750 \\
\hline Transport & 100 & 319 & 98.74465 & 180 & 520 \\
\hline Alcohol & 100 & 128.35 & 84.42633 & 0 & 300 \\
\hline Entertainment & 100 & 244.3 & 70.16942 & 60 & 400 \\
\hline Frequency of Exposure & 100 & 4.21 & 3.242069 & 1 & 12 \\
\hline HIV status ${ }^{*}$ & 100 & 1.26 & 0.440844 & 1 & 2 \\
\hline Perception $^{* *}$ & 100 & 1.36 & 0.643852 & 1 & 4 \\
\hline Perceived Risk $^{* * *}$ & 100 & 1.38 & 0.4878317 & 1 & 2 \\
\hline
\end{tabular}

${ }^{*} 1$ is where the HIV status is known and 2 otherwise. ${ }^{* *} 0$ is when the respondent considers none of the four options to be valuable and 4 is when the respondent considers all of them to be valuable. ${ }^{* * *} 1$ is where the perceived risk is low and 2 where it is high.

monthly engagement in sexual activities of the respondents was 4 times and the maximum number of times that a respondent had engaged in sexual activities in a month is 12 times which is high compared to the frequency of exposure of random respondents who had a minimum of 1 . The students perceived themselves as being at low risk of being infected with HIV which is a characteristic of women who are less likely to use the female condom. This may indicate that the use of the male condom reduces one's perceived risk, thereby reducing the need for consistent female condom use.

\subsection{Empirical Results and Interpretations}

Table 2 gives the odds ratios from logistic regression models association between socio-economic variables and consistent use of the female condom. The probability values of the models are significant $(0.0082,0.0656$ and 0.0492) which shows that the models are a good fit. The dependent variable in the model is the frequency of use of the female condom and the explanatory variables were age, level of education, expenditure (food, rent, transport, alcohol and entertainment), frequency of exposure to HIV (monthly engagement in sexual activities) and perceptions about the female condom.

In this study we observe that age, Frequency of exposure, perception about the female condom and perceived risk of infection had a positive bearing on condom use whereas knowledge about ones HIV status had a negative effect on condom use, albeit at different degrees of significance.

Age was positively related to condom use and statistically significant at 5 percent level. An increase in age results in an increases the odds of frequent use of the female condom. A study done in Spain by Martin [22] found that as women's age increases, they get involved in stable relationships and are able to comfortably negotiate the use of the female condom with a long term partner compared to when they are in a short term relationship.

Having knowledge of one's HIV status is statistically significant and negatively influences the frequent use of the female condom. When one has knowledge about their HIV status, it results in a decrease in the odds of the frequent use of the female condom by a factor of 0.14 . This finding is consistent with the notion by Fapohunda and Biddlecom [23] in a study carried out in Zambia which found that respondents who do not know their HIV status may have promiscuous partners and are more likely to use the female condom as compared to respondents who know their HIV status and make rational decisions in order to either maintain their negative status or avoid being re-infected with HIV.

The number of times that an individual engages in sexual activities is significant and positively influences the 
Table 2. Odds ratios from logistic regression analysis assessing associations between selected variables and the use of the female condom among university students.

\begin{tabular}{ccccccc}
\hline Parameters & Odds Ratio & Std. Error & $\mathbf{Z}$ & $\mathbf{P}>\mathbf{z}$ & \multicolumn{9}{c}{ 95\% Confidence Interval } \\
\hline Age & 1.37164 & 0.2493973 & 1.74 & $0.082^{* * *}$ & 0.9604415 & 1.958886 \\
Food & 0.9995496 & 0.0025392 & -0.18 & 0.859 & 0.9945852 & 1.004539 \\
Rent & 0.9998432 & 0.0010729 & -0.15 & 0.884 & 0.9977426 & 1.001948 \\
Transport & 0.9986711 & 0.0029092 & -0.46 & 0.648 & 0.9929854 & 1.004389 \\
Alcohol & 1.000034 & 0.0035391 & 0.01 & 0.992 & 0.9931219 & 1.006995 \\
Entertainment & 1.002545 & 0.0041423 & 0.62 & 0.538 & 0.9944588 & 1.010696 \\
HIV status & 0.1434584 & 0.1678492 & -1.66 & $0.097^{* * *}$ & 0.0144812 & 1.421178 \\
Frequency of exposure & 1.267651 & 0.1168769 & 2.57 & $0.010^{*}$ & 1.058082 & 1.518729 \\
Perception & 0.3412741 & 0.2583326 & 1.42 & $0.056^{* * *}$ & 0.0774058 & 1.504642 \\
Perceived risk & 5.208204 & 4.931395 & 1.74 & $0.081^{* * *}$ & 0.8141918 & 33.31573 \\
\hline
\end{tabular}

Number of observations $=100 ;$ LR chi2(8) $=20.63$; Log likelihood $=-41.081856$; Prob $>$ chi2 $=0.0082 ;$ Pseudo R2 = 0.2007. ${ }^{*}$ Significant at $1 \%$ confidence level, ${ }^{* *}$ Significant at $5 \%$ confidence level and ${ }^{* * *}$ Significant at $10 \%$ confidence level.

frequent use of the female condom by university students. An increase in the number of times of engaging in sexual activities increases the odds of frequent use of the female condom by a factor of 1.27. A study done by Meekers and Richter [14] in Zimbabwe analysed the factors associated with the use of the female condom and found that women who perceived themselves to have a high risk of HIV infection were more likely to than others to use the female condom.

Perceptions about the female condom are significant and positively affect the frequent use of the female condom. This means that positive perceptions about the female condom's effectiveness for STI and HIV prevention are associated with the use of the female condom by a factor of 0.34 . The results are also consistent with a study done in Zimbabwe by Meekers and Richter [14]. The study found that women generally try the female condom not for family planning purposes but rather for the prevention of HIV/AIDS.

The perceived risk was significant at $10 \%$ and positively affected the use of the female condom by a factor of 5.21. This implies that women with a high perceived risk of HIV infection were more likely to use the female condom compared to women with low perceived risk of HIV. This is consistent with the results found by Dominik and Trussell [24] in Thailand which reported that consumers who perceived themselves to have a low risk or no risk of infection were less likely than others to have used the female condom consistently. This finding was found to be consistent with the notion that respondents who are monogamous but who may have promiscuous partners are more likely than others to use the female condom consistently.

\section{Discussion}

It could have been expected that the sign for age should be negative given that the young people are the ones who are very much at risk of HIV infection. But because of their ages they may be limited by insufficient resources which incapacitated their ability to negotiate the use of the female condom or even safer sex. It could further be attributed to the use of male condoms which could also be perceived to be equally effective.

The observation that those who knew their HIV status used the female condoms less often than those who did not know their status could be attributed to an array of factors. Given that the youth to which this category falls may be infected and as such they may be of the view that they are already positive and care less about their partners. It could also be that they are negative along with their partners and believe and trust their partners and themselves and as such consider their propensity of infection to be minimal. The other possibility is that irrespective of their HIV status or even those of their partners, they use the male condom as a substitute. That the HIV statuses of the respondents in this case were not solicited for makes it difficult to arrive at meaningful conclusions.

The frequency to exposure has an expected positive and highly significant sign. It can be quite controversial 
to maintain that frequency of sexual activity alone is a good proxy of exposure. In cases where the frequency is high and is with a single faithful partner in which case the two are HIV negative, the probability of infection through sexual activity alone is zero if not impossible. It could be that an individual who engages in sexual activity twice or thrice with different individuals will be highly exposed than the one who has thirty episodes per month with the same individual. The lack of follow up questions to determine whether the number of times one had sex in a month was with the same or many individuals compromised our findings.

The perception about risk to HIV infection is one variable that takes into account the respondents beliefs about multifarious factors. Some of the factors may be myths whereas for some other factors the influence on perceptions could vary in some cases in the contrary. However, it is worth noting that irrespective of the factors behind the perceptions, the respondents tended to use female condoms when they perceived some increased risk of infection.

\section{Conclusions}

The study has been able to shed some light on the use of the female condoms. For those predictors of female condom use, it should be borne in mind that it would be erroneous to conclude that less female condom use is synonymous with the absence of safer sexual practices. This is largely because this study has tended to omit the use of the male condom which is a perfect substitute for the female condom. It is only when the two are taken into account that a more acceptable pronouncement may be made on the presence of safe sexual practices or otherwise. Even the two may not necessarily be adequate to make such a pronouncement, for in cases where a couple has negative status and are honestly faithful, it could be argued that unprotected sex is safer sex in their case.

In light of the omissions on the use of the male condom and the faithfulness of partners, it can be concluded that the results of the study are a pronouncement on the use of the female condom and nothing at all on safer sexual practices. It would be invaluable for further studies incorporating these omitted variables to be undertaken in the continued fight against HIV and AIDS. It is only then that relevant information with relevant policy implications can be obtained. However, there is a need for continued sexual education on the importance and relevance of the use of the female condom in an era such as ours, particularly in Botswana in which HIV and AIDS continue to be a major threat to our social and economic wellbeing.

\section{References}

[1] Central Statistics Office (2008) Botswana AIDS Impact Survey III: Statistical Report. Central Statistics Office, Gaborone.

[2] Lamptey, P. and Price, J. (1998) Social Marketing Sexually Transmitted Disease and HIV Prevention; A Consumer-Centered Approach to Achieving Behaviour Change. AIDS, 12, S1-S9.

[3] Bond, V. and Dover, P. (1997) Men, Women and the Trouble with Condoms: Problems Associated with Condom Use by Migrant Workers in Rural Zambia. Health Transition Review, 7, 377-391.

[4] UNAIDS (2005) Report on the Global AIDS Epidemic. UNAIDS, Geneva.

[5] WHO (2005) Newsletter, June. WHO, Geneva.

[6] WHO (2000) Reproductive Health Report. WHO, Geneva.

[7] Gollub, P. and Erica, L. (2000) The Female Condom: Tool for Women's Empowerment. American Journal of Public Health, 90, 1377-1381. http://dx.doi.org/10.2105/AJPH.90.9.1377

[8] UNAIDS (2000) Report on the Global AIDS Epidemic: A UNAIDS 10th Anniversary Special Edition. UNAIDS, Geneva.

[9] UNAIDS (1999) Report on the Global AIDS Epidemic. UNAIDS, Geneva.

[10] Mmegi Newspaper (2010) Female Condom Not So Blissful. Mmegi Newspaper, 27, 26 April 2010.

[11] AIDSCAP (1997) The Female Condom: From Research to the Market Place. United States of America.

[12] WHO (2000) Sentinel Surveillance for HIV Infection: A Method to Monitor HIV Infection Trends in Population Groups. WHO, Geneva.

[13] Hogan, P. and Kitagwa, M. (1985) The Impact of Social Status on Family Structure. American Sociological Review, 59, 408-424.

[14] Brewster, K. (1994) Race Differences in Sexual Activity among Women. American Sociological Review, 59, $408-424$. 
http://dx.doi.org/10.2307/2095941

[15] Meekers, D. and Richter, K. (2005) Factors Associated With Use of the Female Condom in Zimbabwe. International Family Planning Perspectives, 31, 30-37. http://dx.doi.org/10.1363/3103005

[16] Gilbert, M., Middlestadt, S. and Eustace, A. (2000) Using a KAPB Survey to Identify Determinants of Condom Use Among Sexually Active Adults. Journal of Applied Psychology, 25, 1-20.

[17] Harrison, D., David, S., Riehman, K. and Eberstein, I. (1997) Factors Associated With Use of the Female Condom. Family Planning Perspectives, 29, 181-184. http://dx.doi.org/10.2307/2953383

[18] Macaluso, M., Artz, L., Fleenor, M., Robey, L., Kelaghan, J. and Cabral, R. (1997) Female Condom Use among Women at High Risk of Sexually Transmitted Diseases. Family Planning Perspective, 32, 138-44. http://dx.doi.org/10.2307/2648163

[19] Choi, K., Hoff, C., Gregorich, E. and Gomez, C. (2008) The Efficacy of Female Condom Skills Training in HIV Risk Reduction among Women: A randomized Controlled Trial. American Journal of Public Health, 98, 1841-1848. http://dx.doi.org/10.2105/AJPH.2007.113050

[20] Kenneth, S. and Hsiao, C. (2005) Multinomial Logit Specification Tests. International Economic Review, 26, 619-627.

[21] Schmidt, P. and Strauss, R. (1975) The Prediction of Occupation Using Multinomial Logit Models. International Economic Review, 16, 471-486

[22] Martin, S. (2008) AIDS and Behavioral Change to Reduce Risk: A Review. American Journal of Public Health, 78, 394-410.

[23] Fapohunda, O. (2009) Reproductive Health Risk and Protective Factors among Youth in Lusaka, Zambia. Journal of Adolescent Health, 30, 76-86.

[24] Dominik, M. and Trussell, A. (2004) Determinants of Condom Use among Young People. Studies in Family Planning, 33, 335-346. 